\title{
Structure and electrical behavior relationship of a magnesium-tellurite glass using Raman and impedance spectroscopy
}

\author{
S. Terny ${ }^{\text {a,b }}$, M.A. De la Rubia ${ }^{\text {b }}$, R.E. Alonso ${ }^{\text {a }}$, J. de Frutos ${ }^{b}$, M.A. Frechero ${ }^{\text {c,* }}$ \\ a IFLP, Universidad Nacional de La Plata, Departamento de Física, C.C. N 67, 1900 La Plata, Argentina \\ b POEMMA-CEMDATIC, E.T.S.I. Telecomunicación, UPM, Avda. Complutense, 30, 28040 Madrid, Spain \\ c INQUISUR - Universidad Nacional del Sur, Departamento de Química, Av. Alem 1253, 8000 Bahía Blanca, Buenos Aires, Argentina
}

\section{A R T I C L E I N F O}

Article history:

Received 8 October 2014

Received in revised form 10 December 2014

Accepted 19 December 2014

Available online 26 December 2014

\section{Keywords:}

Tellurite glasses;

Impedance spectroscopy;

Raman spectroscopy;

Polaron hopping

\begin{abstract}
A B S T R A C T
In this paper we present the study of the glassy systems of formula: $\mathrm{xMgO}(1-\mathrm{x})\left(0.5 \mathrm{~V}_{2} \mathrm{O}_{5} \cdot 0.5 \mathrm{MoO}_{3}\right) 2 \mathrm{TeO}_{2}$, with $(0<\mathrm{x}<1)$. The aim of the work is to understand the relationship between in the induced changes in the glassy matrix by the incorporation of $\mathrm{MgO}$ in a vanadium-tellurite glass and the electrical response of the material. It has been found that the incorporation of $\mathrm{MgO}$ in the glassy matrix raises the glass transition temperature. The whole system's electrical behavior is explained by the small polaron hopping, in good agreement with the variable range polaron hopping model. In this matrix, an ionic transport by $\mathrm{Mg}^{2+}$ is not allowed. The study gives an opportunity to understand how to tune in the middle-range glassy structural order and, as a direct implication, how to control the electrical conduction process.
\end{abstract}

@ 2014 Published by Elsevier B.V.

\section{Introduction}

Structure and properties of oxides glasses depend strongly on the nature and concentration of network formers, and even more of modifiers. Tellurite glasses are of technical interest because of their low melting points and their absence of hygroscopic properties, which limit the uses of other glasses. These glasses have multiple applications due to their thermal, optical and electric properties being stable at room temperature $[1,2]$. They have low photon energy, high linear and nonlinear refractive index and they are used for the design of photorefractive materials, non-linear devices, up-conversion lasers and optical amplifiers [3].

Many glasses containing transition metal ions, such as vanadium or iron, are semiconductors. It is generally recognized that the conductivity in those glasses is due to the presence of ions with more than one valence state, for instance $\mathrm{V}^{4+}$ and $\mathrm{V}^{5+}$ or $\mathrm{Fe}^{2+}$ and $\mathrm{Fe}^{3+}$. In those systems, an electron can pass from one ion to another and, as a consequence, the electrical conductivity mechanism will be similar to that produced by impurities in ionic crystals, such as $\mathrm{NiO}$ [4].

In every kind of vanadium glasses there is evidence that the energies of an electron are spread over a small range of $\left(k_{B} T\right)$ at room temperature on every vanadium site; being the ligand fields surrounding a $\mathrm{V}^{4+}$ and a $\mathrm{V}^{5+}$, identical. Schmid [5] has suggested that at the temperature at which the glass solidifies, the electron moves rapidly from ion to ion in such a way that the average field acting on the surrounding

\footnotetext{
* Corresponding author.

E-mail address: frechero@uns.edu.ar (M.A. Frechero).
}

atoms during solidification is the same for every vanadium site. This is not necessarily so for all glasses: some glasses containing $\mathrm{Cu}^{+}$and $\mathrm{Cu}^{2+}$-investigated by Drake et al. [6] show a larger activation energy $(\sim 1 \mathrm{eV})$ in their conductivity, suggesting that the sites are not identical; therefore, more energy is needed to move an electron from $\mathrm{Cu}^{+}$on to a $\mathrm{Cu}^{2+}$ site. Glasses containing iron may be intermediate [4].

We have studied previously glassy systems of formula $\mathrm{x}\left(\mathrm{M}_{2} \mathrm{O}\right)$ $(1-\mathrm{x})\left(0.5 \mathrm{~V}_{2} \mathrm{O}_{5} \cdot 0.5 \mathrm{MoO}_{3}\right) 2 \mathrm{TeO}_{2}$ (with $\mathrm{M}=\mathrm{Li}, \mathrm{Ag}$ or $\mathrm{Na}$ ) [7-11]. The electrical conductivity of these systems modified with alkaline oxides showed a deep minimum near $\mathrm{x}=0.5$. The conductivity isotherm of those systems evidences that the polaron conductivity decreases while the ionic conductivity rises. This behavior has not been explored on this matrix for earth alkaline modifiers, thus opening a promissory window to the exploration for new ionic conductor glasses. There are many studies on binary and ternary tellurite glasses modified with alkaline-earth elements [12-23] but there are only a few on quaternary tellurite glasses modified with divalent cations. The aim of this work is to present a structural and an electric study of the glass of formula $\mathrm{xMgO}(1-\mathrm{x})\left(0.5 \mathrm{~V}_{2} \mathrm{O}_{5} \cdot 0.5 \mathrm{MoO}_{3}\right) 2 \mathrm{TeO}_{2}(\mathrm{x}$ : mol number of magnesium oxide in the system) which behaves as a semiconducting glass for all compositions range in order to understand the role of the valence of the modifier ions and the nature of the modifications induced by the presence of transition metal oxides in the structure.

\section{Experimental}

All the glassy compositions have been prepared through the standard melt quenching technique using reagent grade chemicals of 
$\mathrm{TeO}_{2}, \mathrm{MgCO}_{3}, \mathrm{MoO}_{3}$ and $\mathrm{V}_{2} \mathrm{O}_{5}$. Appropriate amounts of the components were weighed properly with a laboratory scale sensitive to $0.1 \mathrm{mg}$, well mixed and placed in a platinum crucible. Next, the decarboxylation process was made at a lower temperature than the mix melting point. When the effervescence finished, the mix was heated to reach $1173 \mathrm{~K}$. All of this process was done in an electric furnace for about $1 \mathrm{~h}$. During the process, the crucible was shaken frequently to ensure homogenization. Then, the molten material was poured on a preheated aluminum plate in form of drops and held at $200{ }^{\circ} \mathrm{C}$ during $2 \mathrm{~h}$ for annealing.

The amorphous character of the samples was tested by X-ray diffraction analysis (XRD) and by differential scanning calorimetry (DSC). Xray diffraction (XRD) patterns of powdered samples after the annealing were collected with a standard Phillips PW-1710 diffractometer provided with a scintillation counter and an exit beam graphite monochromator at room temperature. The samples were exposed to $\mathrm{Cu} \mathrm{K}_{\alpha}$ radiation $\left(\lambda_{\text {average }}=1.5418 \AA\right.$ ) in a $2 \theta$ range of $3^{\circ}$ to $60^{\circ}$.

The glass transition temperatures $\left(\mathrm{T}_{\mathrm{g}}\right)$ of each compositions were determined by differential scanning calorimetry (DSC). DSC curves were recorded using a Q20-0836 at a heating rate of $10{ }^{\circ} \mathrm{C} / \mathrm{min}$ in the temperature range of $(25-400)^{\circ} \mathrm{C}$. The associated upper limit error of the temperature measurements is one degree according to the middle point procedure with the TQA software. The characteristic endothermic peak was associated to $T_{g}$.

Raman spectra were recorded at room temperature in the $0-4000 \mathrm{~cm}^{-1}$ range using a Raman spectrometer with $\lambda=532 \mathrm{~nm}$. The sample focalization was done using a microscope with an $\times 20$ objective. The measurements were performed using a laser power of $42 \mathrm{~mW}$ in order to avoid damage or localized heating of the glasses.

For the electric conductivity measurements the samples were polished with finely grained sandpaper in order to obtain glass disks with parallel faces and thickness between 0.5 and $0.8 \mathrm{~mm}$. Then, both faces of the samples were uniformly coated with a thin layer of silver conducting paint to have proper electrical contact. For the impedance determinations, a Solatron Impedance Analyzer 1260 was used in the frequency range $1.10^{-2} \mathrm{~Hz}-1.10^{7} \mathrm{~Hz}$ with $\mathrm{AC}$ voltage amplitude of $800 \mathrm{mV}$. The impedance $\mathrm{Z}$ and phase angle $\phi$ of each composition have been measured as a function of frequency and temperature. The data was analyzed using the specific software "ZVIEW" in order to obtain the bulk resistance and to calculate the conductivity at each temperature. For each composition the spectra were carried out in a temperature range starting at $25^{\circ} \mathrm{C}$ up to a temperature $15^{\circ} \mathrm{C}$ below $\mathrm{T}_{\mathrm{g}}$ in order to avoid changes in the sample.

Finally, density measurements were done following the Archimedean's method using distilled water as secondary displacement medium. In order to obtain the average density values, three independent measurements were carried out per composition.

\section{Results and discussion}

\subsection{XRD, DSC and density}

Fig. 1 shows the X-ray diffraction patterns. The base line deviation intensity in the pattern (in the range from $20^{\circ}$ to $30^{\circ} 2 \theta$ degrees) is smooth and do not present sharp peaks. From these results we assume that the samples are glasses. But, the composition $\mathrm{x}=1.0$ could not be obtained. After several attempts varying different quenching rates, all of them presented significant peaks in their XRD pattern (not shown) indicating the presence of crystalline phases.

Fig. 2 shows the corresponding $\mathrm{T}_{\mathrm{g}}$ as a function of $\mathrm{x}$ ( $\mathrm{MgO}$ content) for the whole system. From this Fig., we learn that $\mathrm{T}_{\mathrm{g}}$ values increase to around $34 \%$ with the augmentation of the $\mathrm{MgO}$ content (from $\mathrm{x}=$ 0.0 to $x=0.9$ ). According to N. H. Ray [24], the transition temperature of an oxide glass increases with the cross-link density of the network caused by the strength of the bonds it is composed of and the tightness of its packing in the network. Also, they mention that, in general, the cross-linking has a greater effect than the bond strength.

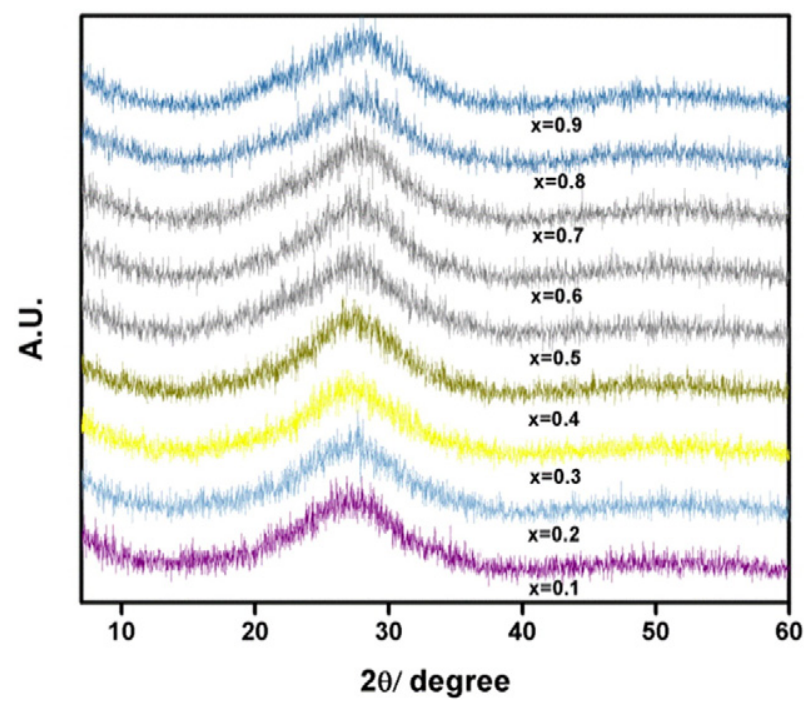

Fig. 1. X-ray diffraction patterns of the systems: $\mathrm{xMgO}(1-\mathrm{x})\left(0.5 \mathrm{~V}_{2} \mathrm{O}_{5} \cdot 0.5 \mathrm{MoO}_{3}\right) 2 \mathrm{TeO}_{2}$ at room temperature.

Fig. 3 shows the density averages as a function of $\mathrm{x} \mathrm{MgO}$ content. There is a tendency to increase its value the replacement of the mix of $\left(\mathrm{V}_{2} \mathrm{O}_{5}+\mathrm{MoO}_{3}\right)$ by $\mathrm{MgO}$; a different behavior is observed for compositions $\mathrm{x}=0.3$ and $\mathrm{x}=0.4$ where the density diminishes. Given that $\mathrm{MgO}$ is lighter than $\left(\mathrm{V}_{2} \mathrm{O}_{5}+\mathrm{MoO}_{3}\right)$ the average increment in the density must be directly related with anomalous peculiar structure ordering.

Fig. 4 shows the molar volume $\left(V_{M}\right)$ and the oxygen packing density. The $\mathrm{V}_{\mathrm{M}}$ diminishes approximately $30 \%$ in the whole replacement of $\left(\mathrm{V}_{2} \mathrm{O}_{5}+\mathrm{MoO}_{3}\right)$ by $\mathrm{MgO}$. Considering a glass as a kind of oxygen polymer - connected by mainly covalent bonds through much smaller linking atoms - the oxygen packing density (OPD: the number of mol of oxygen per $\mathrm{dm}^{3}$ of glass) becomes a relevant magnitude to analyze the compactness of the structure. In this Fig., we observe that the OPD is almost constant when $\mathrm{x}$ goes from $\mathrm{x}=0$ to $\mathrm{x}=0.3$. Then, the packing diminishes from $\mathrm{x}=0.3$ to $\mathrm{x}=0.5$, remaining almost constant up to $\mathrm{x}=0.7$ and, finally, diminishes again. Taking into account that density is a ratio between two quantities which decreasing with the augmentation of the $\mathrm{MgO}$ content (the molar mass of the samples and the molar volume) the resulting density behavior is related to this ratio. As the molar mass can be represented by a linear decreasing function, the

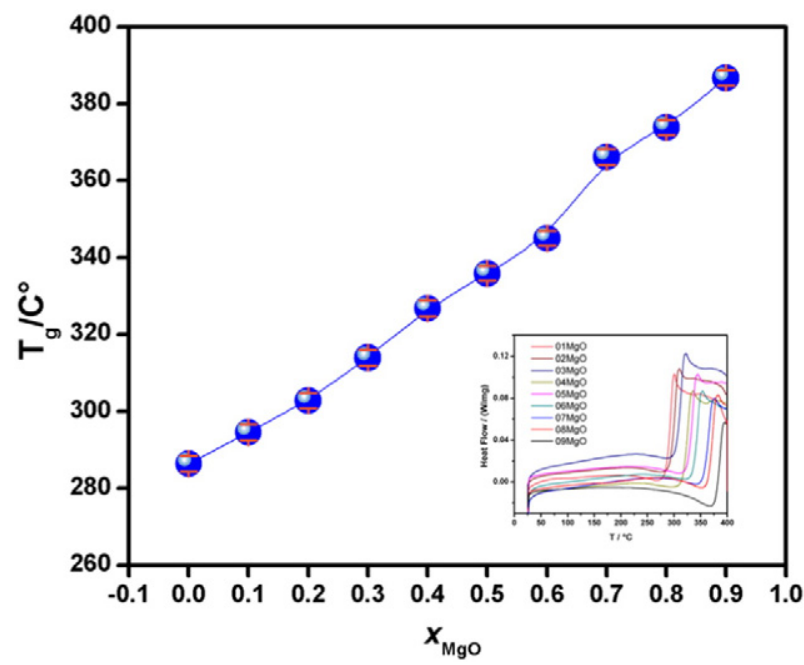

Fig. 2. Glass transition temperature $\left(\mathrm{T}_{\mathrm{g}}\right)$ as a function of $\mathrm{MgO}$ content $(\mathrm{x})$ of the systems: $\mathrm{xMgO}(1-\mathrm{x})\left(0.5 \mathrm{~V}_{2} \mathrm{O}_{5} \cdot 0.5 \mathrm{MoO}_{3}\right) 2 \mathrm{TeO}_{2}$. Inset: DSC scans. 


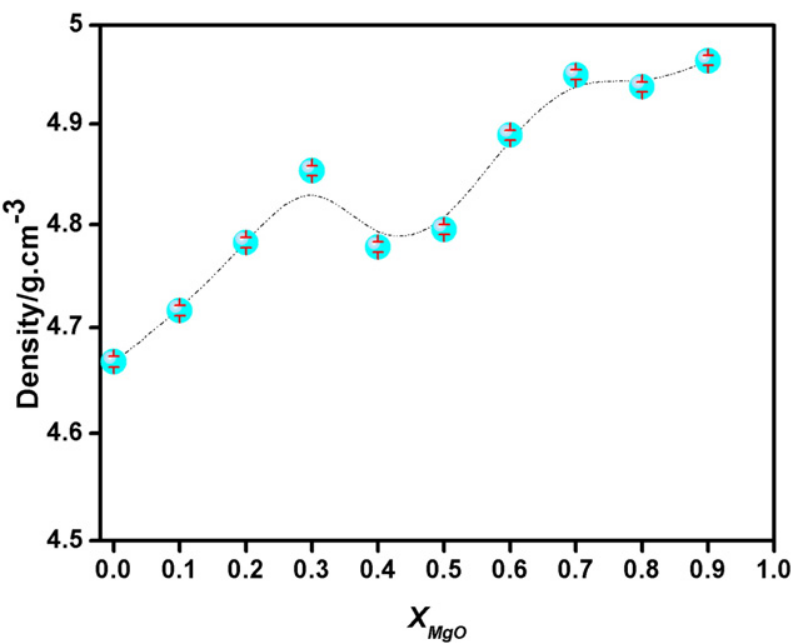

Fig. 3. Density as a function of $\mathrm{MgO}$ content $(\mathrm{x})$ of the systems: $\mathrm{xMgO}(1-\mathrm{x})$ $\left(0.5 \mathrm{~V}_{2} \mathrm{O}_{5} \cdot 0.5 \mathrm{MoO}_{3}\right) 2 \mathrm{TeO}_{2}$.

anomalous variation of the oxygen packing in the range $\mathrm{x}=0.3$ to 0.4 involves a change only in this region. All these observations suggest a strong action given by the incorporation of $\mathrm{MgO}$. The whole OPD variation is almost $10 \%$, which forces the network to a very important atom rearranged in the spatial distribution.

\subsection{Raman analysis}

Raman study for each composition was performed at room temperature. Fig. 5 shows that the overall intensity is composition dependant [25]. This effect may be related with the fact that as the $\mathrm{MgO}$ content increases the rigidness of the structure in good agreement with the above observed $\mathrm{T}_{\mathrm{g}} \mathrm{s}$.

The structure of tellurite glasses and the process of network breaking by the addition of network modifiers have been previously studied by IR absorption and Raman spectroscopy. Sekiya et al. [26] compared the Raman spectra of $\alpha-\mathrm{TeO}_{2}$ and $\beta-\mathrm{TeO}_{2}$ with that of pure $\mathrm{TeO}_{2}$ glass. Also, these authors have studied the Raman spectra of different $\mathrm{TeO}_{2}-$ based glasses. They assigned the deconvoluted Gaussian peaks to the vibrations of different $\mathrm{TeO}_{2}$ structural units [27]. They have observed: a) a peak at $470 \mathrm{~cm}^{-1}$ which is assigned to the stretching and bending vibrations of $\mathrm{Te}-\mathrm{O}$ - Te linkages formed by vertex-sharing $\left[\mathrm{TeO}_{4}\right]$ tbp, $\left[\mathrm{TeO}_{3+\delta}\right]$ polyhedra, and $\left[\mathrm{TeO}_{3}\right]$ tp. The presence of this peak indicates a continuous glass network; b) a peak at $610 \mathrm{~cm}^{-1}$ which is related to the vibration of a continuous network composed of $\left[\mathrm{TeO}_{4}\right]$ tbp; c) an

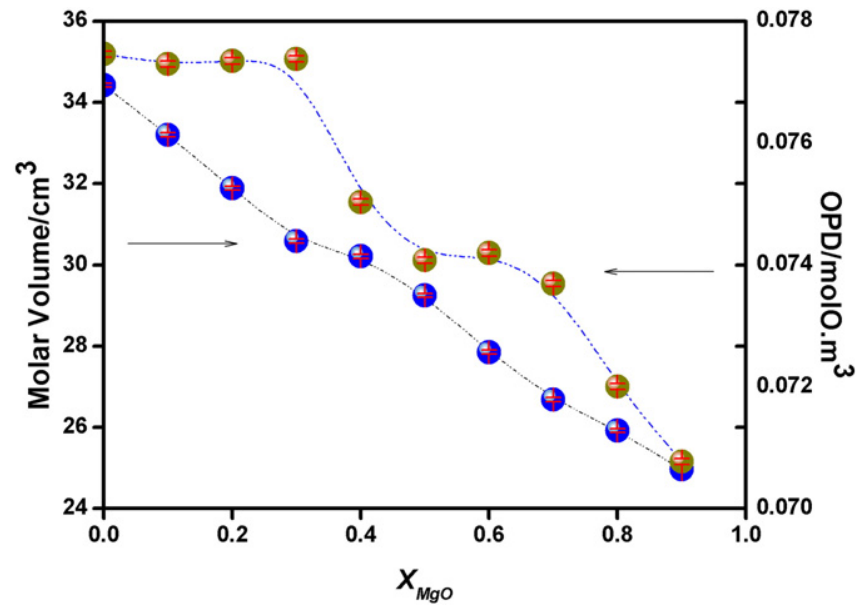

Fig. 4. Molar volume and OPD as a function of $\mathrm{MgO}$ content $(\mathrm{x})$ of the systems: $\mathrm{xMgO}(1-\mathrm{x})$ $\left(0.5 \mathrm{~V}_{2} \mathrm{O}_{5} \cdot 0.5 \mathrm{MoO}_{3}\right) 2 \mathrm{TeO}_{2}$.

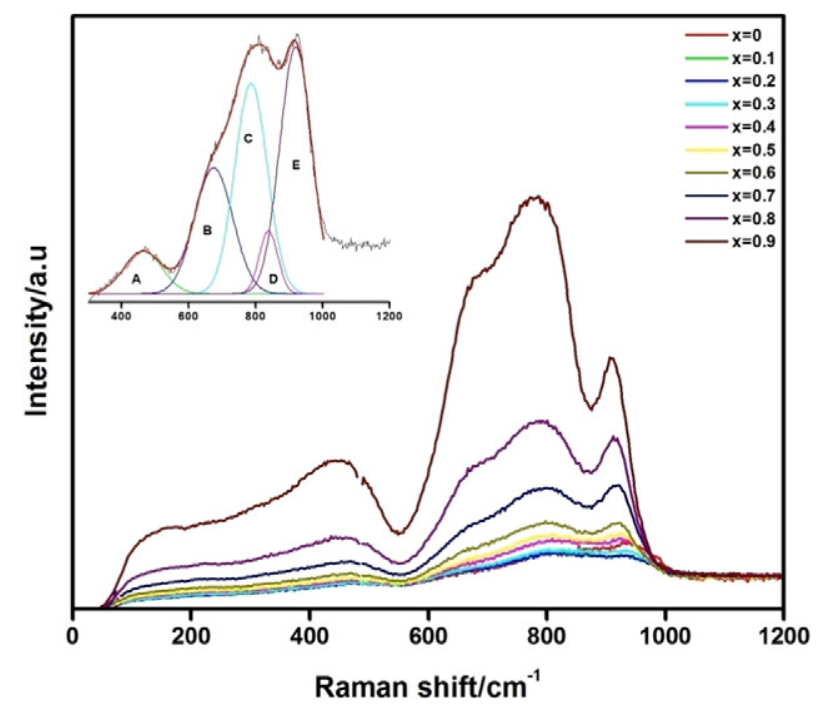

Fig. 5. Raman corrected spectra as a function of $\mathrm{MgO}$ content $(\mathrm{x})$ of the systems: $\mathrm{xMgO}(1-\mathrm{x})\left(0.5 \mathrm{~V}_{2} \mathrm{O}_{5} \cdot 0.5 \mathrm{MoO}_{3}\right) 2 \mathrm{TeO}_{2}$

intense peak at $660 \mathrm{~cm}^{-1}$ which is due to antisymmetric vibrations of $\mathrm{Te}-{ }_{\text {eq }} \mathrm{O}_{\mathrm{ax}}-\mathrm{Te}$ linkages. This peak is also the main peak in the $\alpha-\mathrm{TeO}_{2}$ spectrum since its network comprises $\mathrm{Te}-{ }_{\text {eq }} \mathrm{O}_{\mathrm{ax}}-\mathrm{Te}$ linkages; d) peaks at 720 and $780 \mathrm{~cm}^{-1}$ are assigned to stretching vibrations between $\mathrm{Te}$ and $\mathrm{NBO}$ in $\left[\mathrm{TeO}_{3}+\delta\right.$ ] polyhedra and $\left[\mathrm{TeO}_{3}\right]$ tp units, respectively. The frequency of the vibration depends not only on the linkage but also on the surrounding atoms. Thus, in modified glasses, these frequencies are expected to vary, especially those that involve NBO which strongly interact with the modifiers. Comparing these last data with our results, we can see that they are in good agreement with ours $A, B$ and $C$ bands. Regarding the structural units of $\mathrm{V}_{2} \mathrm{O}_{5}$, in the work of $\mathrm{T}$. Mohamed et al. they have measured and calculated using - ab initio methods - the vibration modes of several tellurite glasses with transition metal oxides as modifiers [28]. In that work they have observed a weak broad band at $905 \mathrm{~cm}^{-1}$ which was assigned to the stretching motion of the double bonded oxygen $(\nu \mathrm{Te}=0)$ in the trigonal pyramid (tp) $\mathrm{TeO}_{(1+2) / 2}$. This band should correspond to our D band. Considering the vibrational modes of $\mathrm{MoO}_{3}$, in the study of $\mathrm{MoO}_{3}-\mathrm{TeO}_{2}$ glasses by T. Sequiya et al. [29] have related two features to molybdenum modes: a sharp peak at $920-940 \mathrm{~cm}^{-1}$ assigned to stretching vibrations $\mathrm{M}=\mathrm{O}$ of the coordination polyhedra of molybdenum atoms and another smoother band at $840-870 \mathrm{~cm}^{-1}$. This last band has two possible different assignments: one is the antisymmetric stretching vibrations of the $\mathrm{Mo}_{\text {short }}-\mathrm{O}_{\text {long }}-\mathrm{Mo}$ linkage associated with $\mathrm{MoO}_{6}$ octahedral having a $\mathrm{Mo}=\mathrm{O}$ and the other is the antisymmetric stretching vibrations of $\mathrm{MoO}_{4}$ tetrahedron having unshared oxygen atoms. Both bands are in correspondence with the $\mathrm{D}$ and $\mathrm{E}$ bands of this work, but the widening produced by the more complex nature of the samples of the present study makes a one-to-one assignment and a differentiation with the $\mathrm{V}_{2} \mathrm{O}_{5}$ band difficult. Finally, as $\mathrm{MgO}$ has no Raman active modes, relevant bands in the vitreous state due to modifications in the magnesium neighborhood are not expected to appear.

Different approaches have been used for other authors to estimate the population of the structural units by means of the analysis of the Raman spectra. For example, in the work of Sequiya et al. they normalize the overall intensity of polarized spectra by dividing the amplitude by the $\mathrm{MoO}_{3}$ content, and without intensity correction to obtain a qualitative estimation [29]. In the present work, we have shown that the overall intensity of the Raman spectra grows with $\mathrm{MgO}$ content. But, the area of the Raman bands cannot be used to observe its variation with composition to have a qualitative estimation of the population of the corresponding structure. Then, we have used the relative area of each band, i.e. the ratio of the area of the single Gaussian function divided by the 
total area under the spectrum. For this purpose, we used the reduced and normalized data as described above and Fig. 6 shows the results. The relative area of band $A$, representing the bending vibrations of $\mathrm{Te}-\mathrm{O}-\mathrm{Te}$ linkages formed by vertex-sharing $\left[\mathrm{TeO}_{4}\right]$ tbp, $\left[\mathrm{TeO}_{3}+\delta\right]$ polyhedra, and $\left[\mathrm{TeO}_{3}\right]$ tp, remains constant over composition. Band $\mathrm{B}$ is almost constant up to $\mathrm{x}=0.6$ and then grows, indicating a greater presence of the antisymmetric vibrations of $\mathrm{Te}-{ }_{\text {eq }} \mathrm{O}_{\mathrm{ax}}-\mathrm{Te}$ linkages. Band $C$ continuously grows from $\mathrm{x}=0.3$ up to $\mathrm{x}=0.8$. This band was previously associated with the vibration modes of the NBO. For $\mathrm{x}$ in the range 0.8-0.9 the relative area has a little drop. Band D has a low population over the whole composition range. It grows in the same range than the $\mathrm{C}$ band and also diminishes for $\mathrm{x}$ between 0.8 and 0.9 . Finally, band $\mathrm{E}$ continuously diminishes its relative area, as expected from the previous assignation to the $\mathrm{MoO}_{3}$ or $\mathrm{V}_{2} \mathrm{O}_{5}$ vibrational modes.

\subsection{Impedance spectroscopy}

In tellurium oxide matrix based glasses two types of electric carriers have been observed: electrons (polarons) and ions according to different oxides incorporated as modifiers. When vanadium oxide is present in glassy matrices, it usually shows mixed valence states, $\mathrm{V}^{\text {reduced }}$ and $\mathrm{V}^{\text {oxidized }}$. Many studies have shown that polaron conductivity is due to the electron transfer between those different valence states [1-4,12, 30]. While an electron moves through the matrix, a distortion emerges which moves together as a whole. This is considered as a quasi-particle and is called the polaron. This conduction process has been analyzed in terms of a phonon assisted tunneling effect commonly named polaron $[12,30]$. When the distortion has an extension which is near the lattice constant, it is named small polaron [13,30]. At a very high phonon frequency $\left(\sim 10^{12} \mathrm{~Hz}\right)$ an electron can move backwards and forwards a number of times before the system relaxes. This is an adiabatic hopping transition. Non-adiabatic small polaron hopping (nASPH) motion appears when an electron hops between two thermally equilibrium sites (an extra term for the probability of hopping has to be considered).

DC conductivity for nASPH can be expressed as [30]:

$\sigma=c \cdot(1-c) \cdot N \cdot \frac{e^{2} a^{2} v_{0}}{6 k_{\mathrm{B}} \mathrm{T}} \cdot \exp [-2 \gamma a] \cdot \exp \left[-\frac{E_{\sigma}}{k_{\mathrm{B}} T}\right]$

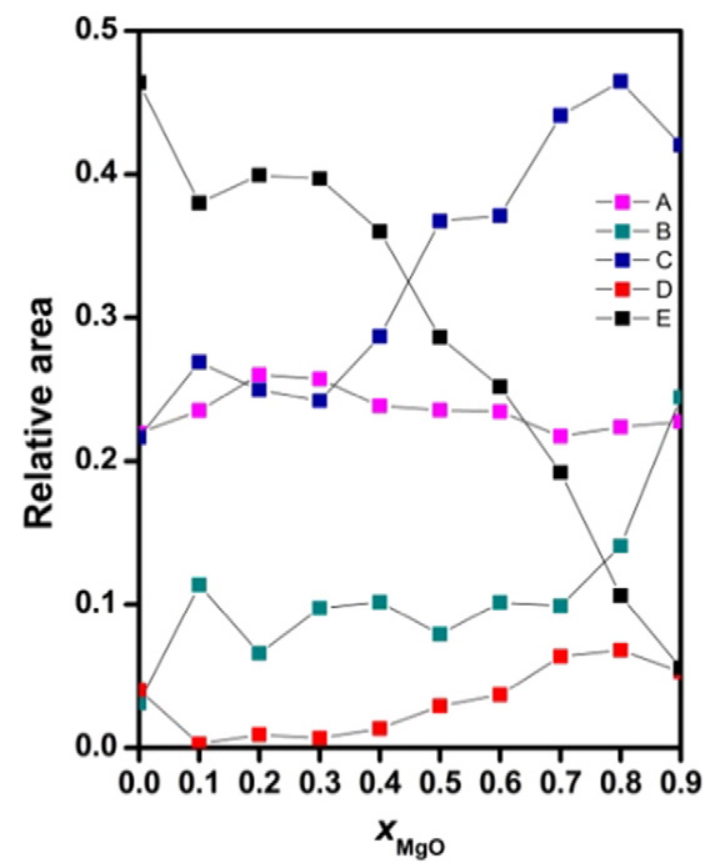

Fig. 6. Relative area of each band as a function of $\mathrm{MgO}$ content ( $\mathrm{x}$ ) of the system: $\mathrm{xMgO}(1-\mathrm{x})\left(0.5 \mathrm{~V}_{2} \mathrm{O}_{5} \cdot 0.5 \mathrm{MoO}_{3}\right) 2 \mathrm{TeO}_{2}$. where $\mathrm{c}$ and $(1-\mathrm{c})$ are the occupied and available sites ( $\mathrm{V}^{\text {reduced }}$ and $\mathrm{V}^{\text {oxidized }}$ ) of the total concentration $\mathrm{N}$; $\mathrm{a}$ is the average distance between two adjacent $\mathrm{V}$ sites with different valence states; $v_{0}$ is the phonon frequency; $\gamma$ is the tunneling factor; $\mathrm{E}_{\mathrm{a}}$ is the activation energy; and $\mathrm{k}_{\mathrm{B}}$ and T have the usual meaning.

Conductivity temperature dependence is usually expressed by the Arrhenius's type equation [31]:

$$
\sigma \cdot T=\sigma_{0} \cdot \exp \left[-\frac{E_{\mathrm{a}}}{k_{\mathrm{B}} T}\right]
$$

Fig. 7 shows the variation of $\log (\sigma \cdot \mathrm{T})$ vs. $\mathrm{T}^{-1}$ for each composition and the corresponding linear fitting according to Eq. (3). The $\mathrm{E}_{\mathrm{a}}$ (activation energy) parameter is plotted vs. MgO content in Fig. 8; the potential barrier can be thermally overcome due to the phonon vibrations in the direction of the $V^{\text {red_}}-V^{\text {oxid }}$ pair [32,33]. The isothermal variation of the electrical conductivity as a function of $\mathrm{x}$ at $500 \mathrm{~K}$ is also shown in Fig. 8.

Previous measurements of electrical conductivity on the ternary system $0.4 \mathrm{TeO}_{2}-0.6\left(\mathrm{yV}_{2} \mathrm{O}_{5}-(1-\mathrm{y}) \mathrm{MoO}_{3}\right)$ were reported [34], in that work has been shown that the conductivity continuously increases and activation energy diminishes with the increase of y (higher $\mathrm{V}_{2} \mathrm{O}_{5}$ content). These facts were related to the electronic (polaronic) conduction phenomenon between transition metal ions with different oxidation states (the "small polaron" model). It was also suggested that only vanadium atoms are involved in the conduction process $\left(\mathrm{V}^{\text {red }} \rightarrow\right.$ $\mathrm{V}^{\text {oxid }}$ ), being the molybdenum ions deeper in energy to be thermally activated. From the FTIR results, Frechero et al. have shown that while molybdenum is homogeneously mixed in the tellurite glassy matrix, vanadium oxide is clearly distinguished from the spectra through its own bands [7]. As the $\mathrm{V}_{2} \mathrm{O}_{5}$ concentration grows, the average distance between two vanadium atoms diminishes, and then the electric conductivity increases. Another important point to take into account is the ratio $\mathrm{V}^{\text {red }} / \mathrm{V}^{\text {oxid }}$. This is conditioned by the composition because it depends strongly on its redox environment [35-37] and something that is expected from the Raman results in this work.

Fig. 8 shows a drastic reduction in conductivity with increasing $\mathrm{MgO}$ content; almost a linear behavior up to $\mathrm{x}=0.6$ and then, a stronger decrease. This behavior is entirely different in tellurite matrices similar to the glass of this work when the modifier oxide is an alkaline oxide or silver oxide. In those glasses what is observed when the alkali cation

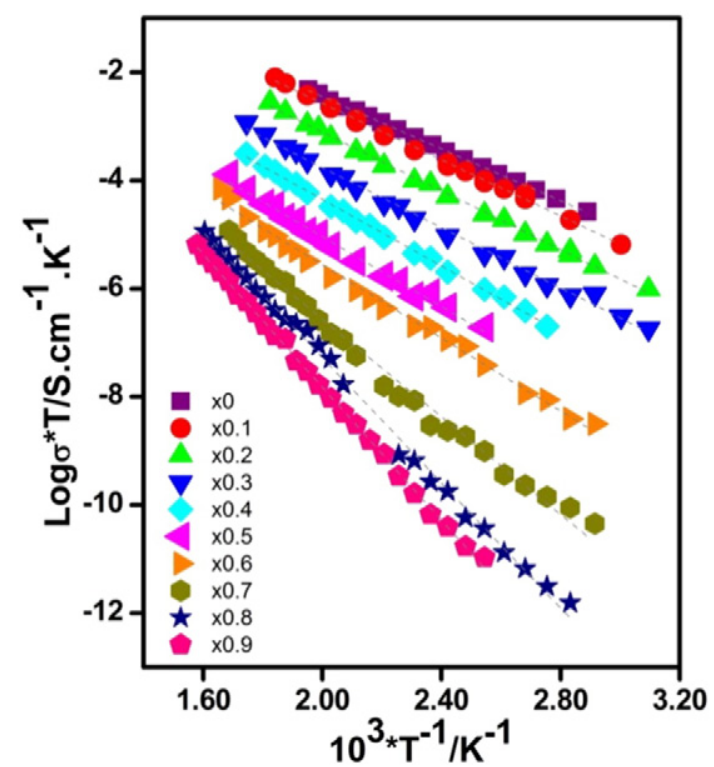

Fig. 7. $\log (\sigma \cdot \mathrm{T})$ as a function of $\left(1000 \cdot \mathrm{T}^{-1}\right)$. Inset: $\mathrm{MgO}$ content $(\mathrm{x})$ of the systems: $\mathrm{xMgO}(1-\mathrm{x})\left(0.5 \mathrm{~V}_{2} \mathrm{O}_{5} \cdot 0.5 \mathrm{MoO}_{3}\right) 2 \mathrm{TeO}_{2} \cdot \mathrm{R}_{(\mathrm{x}=0.0)}^{2}: 0.9995 ; \mathrm{R}_{(\mathrm{x}=0.1)}^{2}: 0.9978 ; \mathrm{R}_{(\mathrm{x}=0.2)}^{2}$ : $0.9980 ; \mathrm{R}^{2}{ }_{(\mathrm{x}=0.3)}: 0.9947 ; \mathrm{R}_{(\mathrm{x}=0.4)}^{2}: 0.9981 ; \mathrm{R}_{(\mathrm{x}=0.5)}^{2}: 0.9911 ; \mathrm{R}_{(\mathrm{x}=0.6)}{ }^{2} 0.9935$; $\mathrm{R}^{2}(\mathrm{x}=0.7): 0.9896 ; \mathrm{R}_{(\mathrm{x}=0.8)}^{2}: 0.9966 ; \mathrm{R}^{2}(\mathrm{x}=0.9): 0.9987$. 


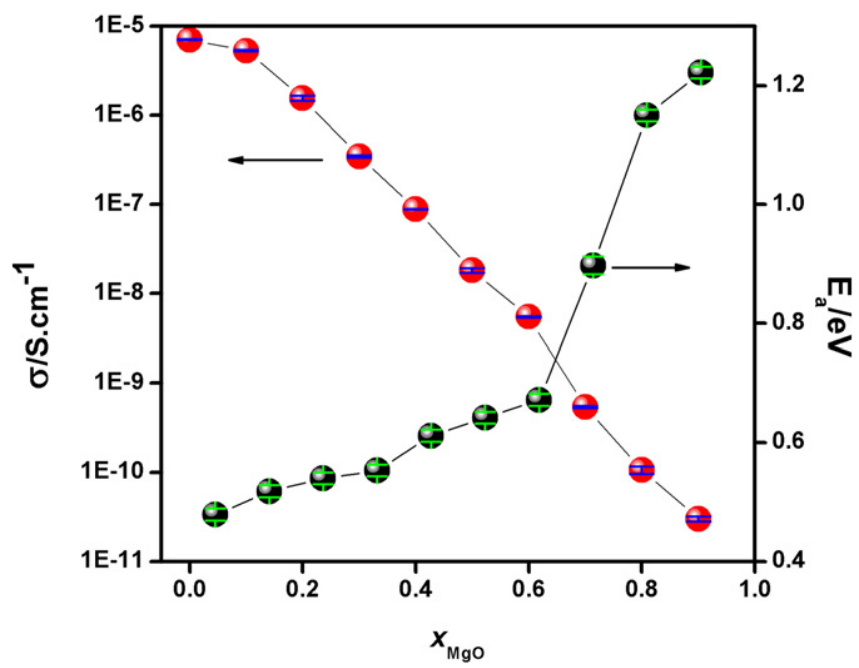

Fig. 8. Conductivity isotherm at $500 \mathrm{~K}$ and activation energy as a function of $\mathrm{MgO}$ content $(\mathrm{x})$ of the systems: $\mathrm{xMgO}(1-\mathrm{x})\left(0.5 \mathrm{~V}_{2} \mathrm{O}_{5} \cdot 0.5 \mathrm{MoO}_{3}\right) 2 \mathrm{TeO}_{2}$.

concentration is high enough is that the ionic conductivity increases and the polaronic conductivity decreases continuously up to be completely negligible $[8,9]$. In the glass of the present work, when the MgO concentration increases by the decreasing of the $\mathrm{V}_{2} \mathrm{O}_{5}$ content (with the consequence of increasing of the $\mathrm{V}^{\text {red }}-\mathrm{V}^{\text {oxid }}$ average distance and the possible change of the $\mathrm{V}^{\text {red }} / \mathrm{V}^{\text {oxid }}$ ratio) a decrease in the electronic (polaronic) conduction mechanism with an increase in the activation energy is observed. Fig. 8 shows an increase to more than twice and a decrease of the conductivity close to six orders of magnitude over the entire range of compositions. Moreover, for $\mathrm{x}=0.6$ and above, the $\mathrm{E}_{\mathrm{a}}$ changes with a steeper slope, indicating that the conductivity path made by the $\mathrm{V}^{\mathrm{red}}$ $\mathrm{V}^{\text {oxid }}$ path is strongly interrupted as we can infer from our Raman results. Consequently, the slope of the isotherm of conductivity (Fig. 8) shows a more negative behavior. Thus, this glassy system has a tendency to be a more and more insulating material as $\mathrm{x}$ approaches 1 .

To support further the idea of the polaron hopping model in the present system, we analyzed our results considering the so-called variable range hopping mechanism [38] given by:

$\sigma=\sigma_{0} \cdot \exp \left[-\left(\frac{T_{0}}{T}\right)^{1 / 4}\right]$

where $\sigma_{0}$ and $T_{0}$ are the constants and $T_{0}$ is given by:

$T_{0}=16^{3} / k_{\mathrm{B}} N\left(E_{\mathrm{F}}\right)$

where $\mathrm{N}\left(\mathrm{E}_{\mathrm{F}}\right)$ is the density of states at the Fermi level.

We show in Fig. 9, the DC conductivity as a function of $\mathrm{T}^{-1 / 4}$. From this fig. (taking into account the excellent linearity of our experimental data as we report there), we confirm the mechanism proposed in the whole range of temperature and composition studied.

\section{Conclusions}

The study of $\mathrm{xMgO}(1-\mathrm{x})\left(0.5 \mathrm{MoO}_{3} 0.5 \mathrm{~V}_{2} \mathrm{O}_{5}\right) 2 \mathrm{TeO}_{2}(\mathrm{x}=0-0.9)$ glasses prepared by melt quench method has shown that: the density of the glasses increases with $\mathrm{MgO}$ content, while OPD and $\mathrm{V}_{\mathrm{M}}$ decrease; differential scanning calorimetry has showed that the glass transition temperature increases with the MgO content; and the Raman spectra have showed the typical bands of corresponding tellurium and vanadium polyhedra that are almost not affected by the presence of $\mathrm{MgO}$ until it reaches a high concentration $(x>0.6)$.

Then, the incorporation of $\mathrm{MgO}$ in tellurite glassy matrices promotes better glassy matrix stability and thermal properties and it does not

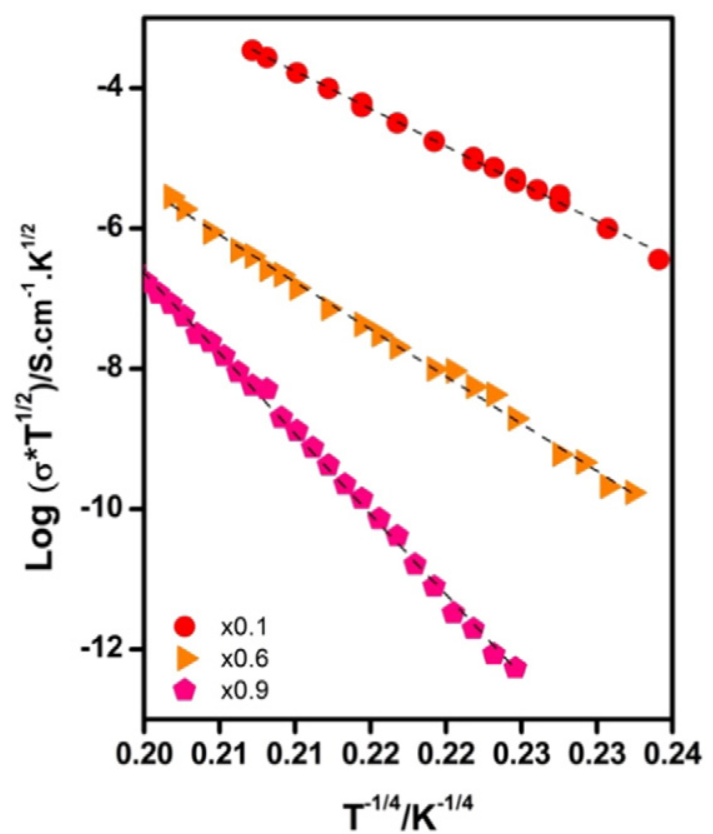

Fig. 9. $\log \left(\sigma \cdot \mathrm{T}^{1 / 2}\right)$ as a function of $\mathrm{T}^{-1 / 4}$. Inset: $\mathrm{MgO}$ content $(\mathrm{x})$ of the systems: $\mathrm{xMgO}(1-\mathrm{x})\left(0.5 \mathrm{~V}_{2} \mathrm{O}_{5} \cdot 0.5 \mathrm{MoO}_{3}\right) 2 \mathrm{TeO}_{2} \cdot \mathrm{R}^{2}(\mathrm{x}=0.1): 0.9973 ; \mathrm{R}^{2}(\mathrm{x}=0.6): 0.9960 ;$ $\mathrm{R}^{2}(\mathrm{x}=0.9): 0.9978$.

impede the electrical conductivity through the verified polaron hopping mechanism. The electrical conductivity response has been reduced by six orders of magnitude in the whole composition system due to the increase in the distance between the $\mathrm{V}^{\mathrm{red}}-\mathrm{V}^{\text {ox }}$ centers and the possible change in the $\mathrm{V}^{\mathrm{red}} / \mathrm{V}^{\mathrm{ox}}$ ratio. From the results presented in this work we cannot consider $\mathrm{Mg}^{2+}$ cation as a potential charge carrier in this kind of tellurite glassy system in order to obtain ionic conductivity behavior in the studied glass.

\section{Acknowledgment}

This work has been possible to the financing of the Spanish MINECO (project MAT2010-C21088-C03), ARCOIRIS ERASMUS MUNDUS ACTION 2 Lot 16A (Argentine). Financial support by the CONICET and the Universidad Nacional del Sur is gratefully acknowledged. S.T. is a fellow of the CONICET. R.E.A. and M.A.F. are research fellows of the CONICET of Argentina.

\section{References}

[1] G. Vijaya Prakash, D. Narayana Rao, A.K. Bhatnagar, Solid State Commun. 119 (2001) 39-44.

[2] N.B. Mohamed, A.K. Yahya, M.S.M. Deni, S.N. Mohamed, M.K. Halimah, H.A.A. Sidek, J. Non-Cryst. Solids 356 (2010) 1626-1630.

[3] J. Ozdanova, H. Ticha, L. Tichy, J. Non-Cryst. Solids 355 (2009) 2318-2322.

[4] G. Austin, N.F. Mott, Adv. Phys. 18 (71) (1969) 41-102.

[5] A.P. Schmid, J. Appl. Phys. 39 (1968) 3140-3149.

[6] C. Drake, I. Scanlan, A. Engel, Phys. Status Solidi 32 (1969) 193-208.

[7] M.A. Frechero, O.V. Quinzani, R.S. Pettigrosso, M. Villar, R.A. Montani, J. Non-Cryst. Solids 353 (2007) 2919-2925.

[8] E. Cardillo, R. Montani, M.A. Frechero, J. Non-Cryst. Solids 356 (50-51) (2010) $2760-2763$

[9] R. Montani, M.A. Frechero, Solid State Ionics 177 (33-34) (2006) 2911-2915.

[10] M.A. Frechero, C.S. Terny, E.C. Cardillo, Lithium Glasses: Improvements as Solid Electrolyte (Book Chapter) Lithium: Technology, Performance and Safety, Nova Science Publishers, Inc., 2013. (ISBN: 978-162417634-0).

[11] M.A. Frechero, P.E. diPrátula, E. Cardillo, S. Terny, Molybdenum oxide. Its positive action on ionic glasses conductors, Molybdenum: Chemical and Electrochemical Properties, Geological Implications and Industrial Applications, Nova Science Publishers, Inc., 400 Oser Avenue, Suite 1600. Hauppauge, NY 11788, 2014 (ISBN: 978-1-63321210-7).

[12] H. Hirashima, T. Yoshida, J. Non-Cryst. Solids 95 and 96 (1987) 817-824.

[13] T. Sekiya, N. Mochida, A. Ohtsuka, J. Non-Cryst. Solids 168 (1994) 106-114. 
[14] Y. Kowada, K. Morimoto, H. Adachi, M. Tatsumisago, T. Minami, J. Non-Cryst. Solids 196 (1996) 204-209.

[15] B. Roling, M.D. Ingram, J. Non-Cryst. Solids 265 (2000) 113-119.

[16] G. Senthil Murugan, Y. Ohishi, J. Appl. Phys. 96 (2004) 2437-2442.

[17] G. Senthil Murugan, Y. Ohishi, J. Non-Cryst. Solids 351 (2005) 364-371.

[18] S. Szu, F. Chang, Solid State Ionics 176 (2005) 2695-2699.

[19] A. Nishara Begum, V. Rajendran, Mater. Lett. 61 (2007) 2143-2146.

[20] A. Chagraoui, Z. Ramzi, A. Tairi, A. Mandil, M. Talibouridah, K. Ajebli, Y. Abboud, J. Mater. Process. Technol. 209 (2009) 3111-3116.

[21] M. Pant, D. Kanchan, N. Gondaliya, Mater. Chem. Phys. 115 (2009) 98-104.

[22] T. Hayakawa, M. Hayakawa, M. Nogami, P. Thomas, Opt. Mater. 32 (2010) 448-455.

[23] T. Komatsu, N. Ito, T. Honma, V. Dimitrov, Solid State Sci. 14 (2012) 1419-1425.

[24] N.H. Ray, J. Non-Cryst. Solids 15 (3) (1974) 423-434.

[25] D.A. Long, Raman Spectroscopy, McGraw-Hill, New York, 1977. (ISBN 9780070386754)

[26] T. Sekiya, N. Mochida, A. Ohtsuka, M. Tonokawa, J. Ceram. Soc. Jpn. 97 (12) (1989) 1435-1440.
[27] T. Sekiya, N. Mochida, A. Ohtsuka, M. Tonokawa, J. Non-Cryst. Solids 144 (2-3) (1992) 128-144.

[28] T.A. Mohamed, I. Shaltout, K.M. Al Yahyaei, Spectrochim. Acta A 64 (2006) 106-115

[29] T. Sequiya, N. Mochida, S. Ogawa, J. Non-Cryst. Solids 185 (1995) 135-144.

[30] S. Szu, Shing-Gwo Lu, Physica B 391 (2007) 231-237.

[31] H.R. Killias, Phys. Lett. 20 (1) (1966) 5-6.

[32] L. Murawski, C.H. Chung, J.D. Mackenzie, J. Non-Cryst. Solids 32 (1979) 91-96.

[33] N.F. Mott, J. Non-Cryst. Solids 1 (1968) 1-17.

[34] N. Lebrun, M. Lévy, J.L. Souquet, Solid State Ionics 40-41 (1990) 718-722.

[35] B.B. Das, D. Mohanty, Indian J. Chem. 45 (2006) 2400-2405.

36] S. Sen, A. Ghosh, J. Appl. Phys. 86 (4) (1999) 2078-2082.

[37] S. Sen, A. Ghosh, J. Appl. Phys. 87 (7) (2000) 3355-3359.

[38] N.F. Mott, E.A. Davis, Electronic Process in Non-crystalline Material, 2nd ed.Clarendon Oxford, 1979 (ISBN 0198512597 ). 